\section{Nunca es tarde en el espacio redundante}

It's never late in redundancy space

Sebastián Lambert
Resumen It's Never Late in Redundancy Space es un videojuego independiente de 6 minutos de duración que intenta discutir sobre la redundancia como un modelo espacio-temporal globalmente normalizado que permanece incuestionado a la luz de la aceleración y la acumulación. Perdido en los pasillos de un centro de datos, el jugador deambula recogiendo unas misteriosas piedras en un bucle interminable acompañado de voces en off y animaciones.

La redundancia es una fórmula ampliamente repetida que asegura el funcionamiento continuo de nuestras ciudades, ecosistemas y redes en caso de fallas, mediante la multiplicación preventiva de algunas o todas las partes del sistema. Es también un instrumento político que, bajo el capitalismo de vigilancia, ha adoptado su última configuración espacial en los centros de datos.

¿Tiene el diseño agencia en el problema de la redundancia?

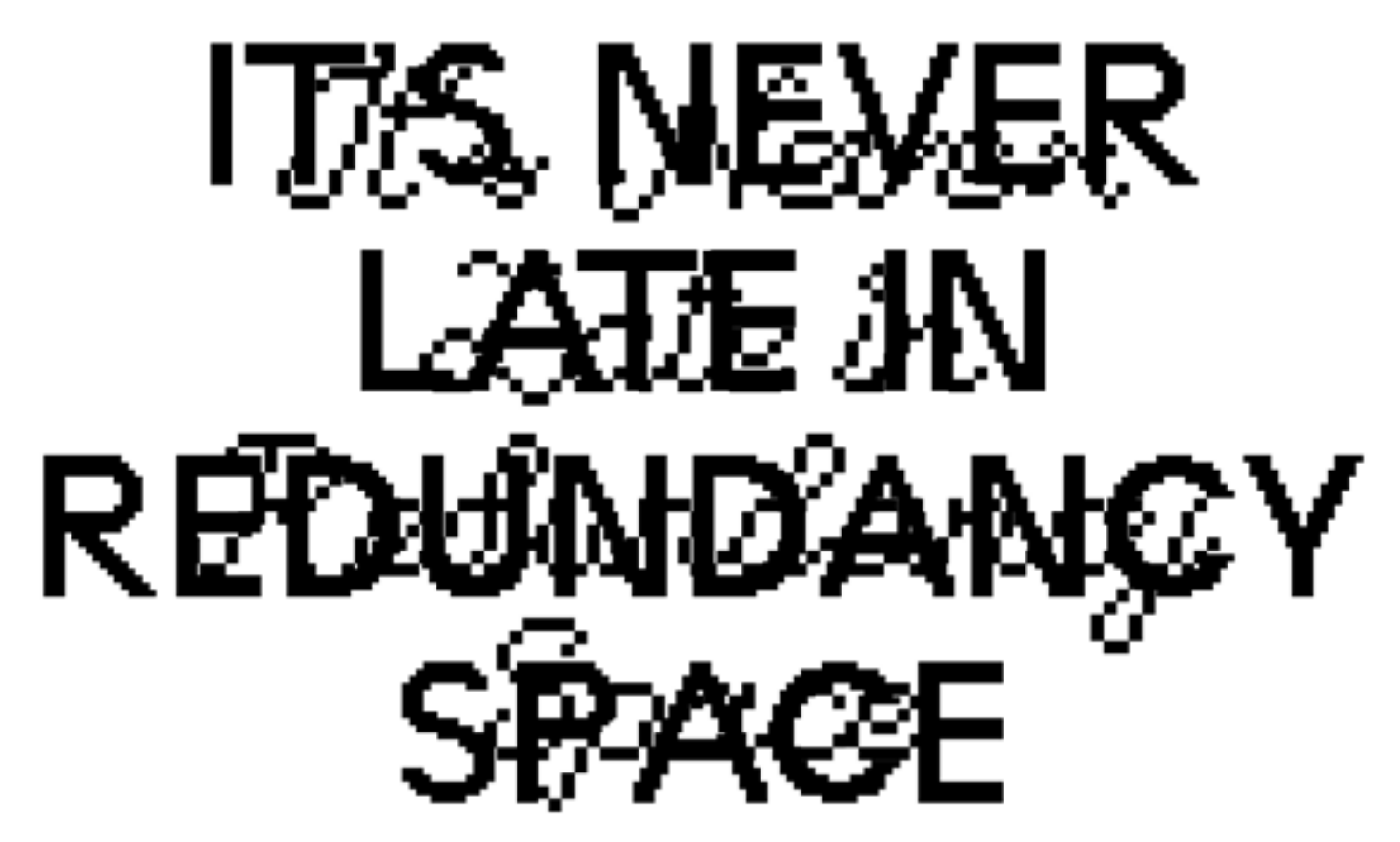

Palabras Clave 

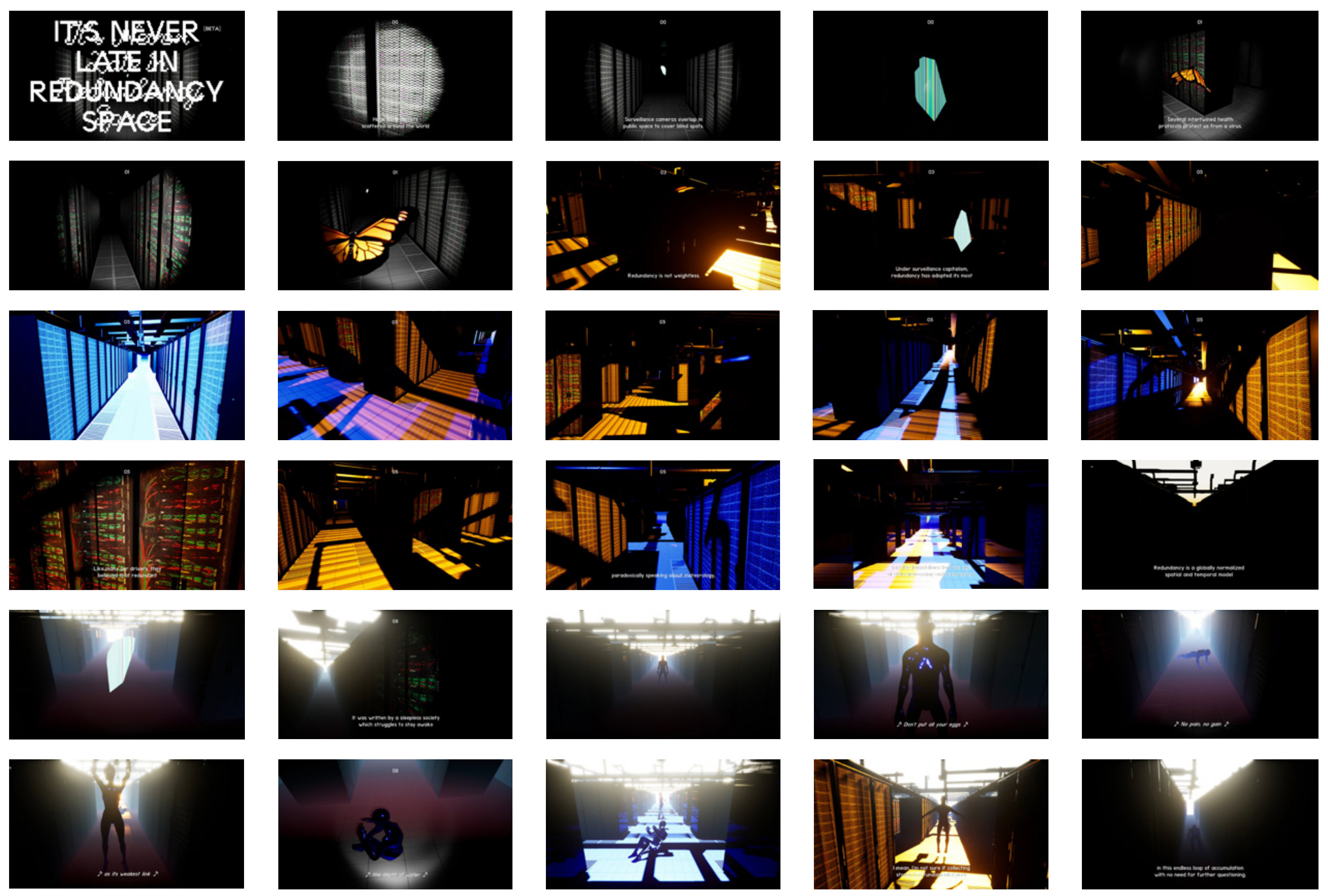
Junta tantas piedras como puedas!

Usa las teclas W, A, S, D y el mouse para moverte.

Haz click para comenzar

Haz click para pausar.

Enormes centros de datos dispersos por todo el planeta duplican sus componentes para garantizar la actividad del sistema. Cámaras de vigilancia se superponen en el espacio público para cubrir puntos ciegos. De acuerdo a la hipótesis de la equivalencia funcional múltiples especies polinizan las mismas flores de forma redundante. Humanos ocupan puestos de trabajo inoperativos para mantener a las empresas en funcionamiento. Varios protocolos de salud entrelazados nos protegen de un virus. Aviones evitan desastres incorporando componentes redundantes. Diferentes agencias policiales operan en distritos legales coincidentes. Varios niveles de la administración pública realizan funciones idénticas. Empresas compiten para vender los mismos servicios o productos.

La redundancia es una fórmula ampliamente repetida que asegura el funcionamiento continuo de nuestras ciudades, ecosistemas y redes en caso de fallas. Funciona mediante un principio muy simple: la multiplicación preventiva de algunas o todas las partes de un sistema.
La redundancia no es ingrávida. Deja huella. Tiene costo. Algunos pueden permitírsela, y otros pagan las consecuencias. Bajo el capitalismo de vigilancia, la redundancia ha adoptado su configuración espacial más avanzada en los centros de datos. Ahora es el principal medio propagandístico de esta industria que crece exponencialmente y que no puede detenerse. ¿Qué sucede cuando la existencia de redundancia anima a los individuos u organizaciones a incrementar el riesgo en un sistema? :Qué pasa si las partes redundantes de un sistema se sincronizan en una falla de modo común catastrófica? ¿Es la redundancia la espacialización de nuestra creciente incapacidad para distinguir entre simulación y realidad?

En el desastre del transbordador espacial Challenge del 1986, los responsables de la toma de decisiones no consideraron la posibilidad de que las frías temperaturas redujeran la resistencia de ambas juntas tóricas en la unión de refuerzo. Como muchos conductores de automóviles, ellos confiaban en que los dispositivos de seguridad redundantes les permitirían despegar en condiciones peligrosas. Ante esta y otras crisis, los humanos tendemos a repetir inconscientemente la afirmación con la que John Von Neumann, paradójicamente hablando de meteorología, sentó las bases de esta era de procesamiento de datos y redundancia: Predeciremos todos los procesos estables, controlaremos todos los procesos inestables.

La redundancia es un modelo espacial y temporal globalmente normalizado que permanece incuestionable a la luz de la aceleración y la acumulación. Es un instrumento político oculto que brinda infraestructura global a las nociones individualizadas de la seguridad, la resiliencia, la comodidad, el bienestar, la superación personal y los cuidados personales en un mundo descuidado.

Por favor, escuchemos juntos una canción. Fue escrita por una sociedad insomne que lucha por mantenerse despierta y sincronizada con la red automatizada sin tener en cuenta los daños ambientales o psicológicos consecuentes. La música y la melodía fueron generadas por una inteligencia artificial en línea.

No pongas todos tus huevos en una misma canasta No pain, no gain

Una cadena es tan fuerte como su eslabón más débil La ignorancia es una bendición

Nunca pruebes la profundidad del agua con ambos pies

No se puede hacer una tortilla sin romper huevos

Nunca dejes para mañana lo que puedas hacer hoy
Bueno, ¡Eso sí que fue una performance! Me estaba preguntando... ¿Cuántas piedras has juntado hasta ahora? Quiero decir, no estoy del todo segura de que juntar piedras sea una parte fundamental de este videojuego. Incluso tengo la impresión de que podrías quedarte para siempre en este bucle de acumulación interminable sin necesidad de hacer más preguntas. De todas formas, y dado que esto es sólo una simulación, quizás puedas presionar escape en cualquier momento para terminar el juego. No lo sé. En cualquier caso, fue un placer conocerte.

\section{Bibliografía}

Bridle, James, New Dark Age: Technology and the End of the Future. London: Verso, 2018

Chatzidakis, Andeas, Jamie Hakim, Jo Litter, Catheine Rottenberg, and Lynne Segal, The Care Manifesto: The Politics of Interdependence. London: Verso, 2020

Crary, Jonathan, 24/7: Late Capitalism and the Ends of Sleep. London: Verso, 2013.

Easterling, Keller, Extrastatecraft: The Power of Infrastructure Space. London: Verso, 2014.

de Arquitectura en Faciseño y Urbanisno (FADU). en Montevideo, Uruguay. Desarrolla proyectos de videoarte y nuevos medios sobre las implicancias político-espaciales de la arquitectura, la información y las imagenes. Su trabajo fue expuesto en el simposio Deep City: Climate Crisis, Democracy and the Digital organizado por la EPFL en Suiza. Es colaborador docente en FADU y coordinador de proyectos en MAPA arquitectos (Uruguay-
Himmelsbach, Sabine, and Claudia Mareis, eds., Poetics and Politics of Data. Basel: Christoph Merian Verlag, 2015.

Laparelli, Ippolito Pestellini. "Data Architectures."
Intelligence. E-flux. Accessed March 1, 2020. https:// www.e-flux.com/architecture/intelligence/310404/dataarchitectures/.

Metahaven. "Captives of the Cloud, Part III: All Tomorrow's Clouds.” E-flux. 2013. https://www.e-flux. com/journal/50/59988/captives-of-the-cloud-part-iii-alltomorrow-s-clouds/.

Verzier, Marina Otero, and Francien van Westrenen, eds., I See That I See What You Don't See. Rotterdam: Het Nieuwe Instituut, 2020.

https://vimeo.com/525397464 